\title{
Circulating $\beta$ Chemokine and MMP 9 as Markers of Oxidative Injury in Extremely Low Birth Weight Infants
}

\author{
GIRIJA NATARAJAN, SEETHA SHANKARAN, SCOTT A. MCDONALD, ABHIK DAS, BARBARA J. STOLL, \\ ROSEMARY D. HIGGINS, POUL THORSEN, KRISTIN SKOGSTRAND, DAVID M. HOUGAARD, AND WALDEMAR A. CARLO; \\ FOR THE NICHD NEONATAL RESEARCH NETWORK

\begin{abstract}
Department of Pediatrics [G.N., S.S.], Wayne State University School of Medicine, Detroit, Michigan 48201; Statistics and Epidemiology [S.A.M], International [RTI], Research Triangle Park, North Carolina 27709; Statistics and Epidemiology [A.D.], RTI International, Rockville, Maryland 20852; Department of Pediatrics [B.J.S.] and Rollins School of Public Health [P.T.], Emory University, Atlanta, Georgia 30322; Pregnancy and Perinatology Branch [R.D.H.], Eunice Kennedy Shriver National Institute of Child Health and Human Development National Institutes of Health, Bethesda, Maryland 20892; Department of Epidemiology and Social Medicine [P.T.], University of Aarhus, Aarhus DK 8000, Denmark; Department of Clinical Biochemistry and Immunology [K.S., D.M.H.], Statens Serum Institut, Copenhagen 2300, Denmark; Department of Pediatrics [W.A.C.], University of Alabama at Birmingham, Birmingham, Alabama 35294
\end{abstract}

\begin{abstract}
Matrix metalloproteinases (MMPs) and chemokines seem to be induced by hyperoxia in preclinical studies. We hypothesized that $\mathrm{O}_{2}$ exposure immediately after birth is associated with altered blood spot MMP 9 and $\beta$ chemokine concentrations. The following analytes were measured on blood spots on $\mathrm{d} 1$ and 3 of life, using luminex technology in 1059 infants (birth weights $<1000 \mathrm{~g}$ ) in the NICHD Neonatal Research Network: MMP 9, monocyte chemoattractant protein 1 (MCP 1), macrophage inflammatory proteins ( $1 \alpha$ and $\beta$ ), and regulated upon activation, normal t cell expressed and secreted (RANTES). Infants administered $\mathrm{O}_{2}$ continually from 6 to $24 \mathrm{~h}$ of life $(n=729)$, when compared with those with $<6 \mathrm{~h}$ exposure $(n=330)$, had significantly lower mean birth weight and higher rate of respiratory distress syndrome $(p<0.002)$. On $\mathrm{d} 3$, MCP 1 was higher and RANTES lower among infants with early prolonged $\mathrm{O}_{2}$ exposure. After adjusting for covariates, prolonged early $\mathrm{O}_{2}$ exposure retained a statistically significant association with higher MCP 1 on d 3 ( $p=0.003$ ). The consistent association between $\mathrm{O}_{2}$ exposure and MCP 1 among extremely preterm infants suggests that further investigation of its role in oxidative injury is warranted. (Pediatr Res 67: 77-82, 2010)
\end{abstract}

$\mathrm{E}^{\mathrm{x}}$ xposure of extremely preterm infants to high concentrations of oxygen $\left(\mathrm{O}_{2}\right)$ has been causally linked to several neonatal morbidities, such as bronchopulmonary dysplasia (BPD), retinopathy of prematurity, and periventricular white matter injury (1-3). In addition, a dysregulated inflammatory response is considered a major contributory factor in the development of these morbidities (4-6). Inflammation and oxidative stress share overlapping mechanisms and potentiate

Received February 18, 2009; accepted September 6, 2009

Correspondence: Girija Natarajan, M.D., Division of Neonatology, Children's Hospital of Michigan, 3901 Beaubien Boulevard, Detroit, MI 48201; e-mail: gnatara@med. wayne.edu

Supported by Eunice Kennedy Shriver National Institute of Child Health and Human Development and the Department of Health and Human Services Grants U10 HD21385, U10 HD40689, U10 HD27871, U10 HD21373, U10 HD36790, U10 HD40461, U10 HD34216, U10 HD21397, U10 HD27904, U10 HD40492, U10 HD27856, U10 HD40521, U10 HD27853, U10 HD27880, U10 HD27851, and R03 HD054420 and National Institutes of Health Grants GCRC M01 RR 08084, M01 RR 00125, M01 RR 00750, M01 RR 00070, M01 RR 0039-43, M01 RR 00039, and 5 M01 RR00044.

Supplemental digital content is available for this article. Direct URL citations appear in the printed text and are provided in the HTML and PDF versions of this article on the journal's Web site (www.pedresearch.org). each other. During inflammation, activated macrophages release oxygen free radicals, which in turn cause the release of proinflammatory mediators (7). Oxygen has been shown to induce inflammation in the heart, lungs, and brain with the activation of metalloproteinases and cytokines $(8,9)$. Whether and how oxidative injury is linked to inflammation has not been directly examined in human neonates.

Matrix metalloproteinases (MMPs) are a group of zincdependent endopeptidases involved in the pathogenesis of tissue injury and wound healing in the endothelium, lung, and myocardium $(10,11)$. Preclinical studies suggest that MMPs may be linked to oxidative injury, with free radicals inducing MMP gene expression (12). In a hypoxic piglet model, proMMP 9 increased in the pulmonary tissue, and MMP 9 levels increased in bronchoalveolar lavage fluid after resuscitation with $100 \%$ oxygen compared with room air, suggesting that these changes were triggered by oxidative stress (13). In another study, MMP 9 activity in hyperoxia ( $>80 \%$ oxygen for 24 to $120 \mathrm{~h}$ )-induced lung injury in a pig model correlated significantly with blood oxygen tension and neutrophils in broncho-alveolar lavage fluid (14). Significant correlations have been reported between protein carbonyl concentrations, a measure of protein oxidation, and MMP 9 levels in bronchoalveolar lavage fluid from ventilated newborns (15). Hyperoxia seems to induce MMPs, setting up a cycle of events culminating in lung injury.

Chemotactic cytokines ( $\beta$ chemokines) are a superfamily of structurally related proteins involved in leukocyte trafficking and activation, which like the MMPs, seem to be induced by hyperoxia in several animal species (16-18). Monocyte chemoattractant protein 1 (MCP 1), macrophage inflammatory proteins (MIP $1 \alpha$ and $\beta$ ), and regulated upon activation, normal T-cell expressed and secreted (RANTES) are some of the chemotactic cytokines. Newborn rats exposed to $95 \%$

Abbreviations: $\mathbf{F i O}_{\mathbf{2}}$, fractional inspired oxygen; MCP 1, monocyte chemoattractant protein 1; MIP, macrophage inflammatory proteins; MMP, matrix metalloproteinase; RANTES, regulated upon activation, normal T-cell expressed and secreted 
oxygen demonstrated a significant induction of MCP 1 in bronchoalveolar lavage fluid between d 2 and 7 of exposure, when compared with controls exposed to air $(19,20)$. Antichemokine treatment on d 3 and 4 partially prevented neutrophil influx, alveolar septal thickening, and decreased tissue carbonyls (19,20). An interaction between chemokines and oxidative stress has been reported, and a possible pathogenic role attributed in adults with acute coronary syndromes or undergoing hemodialysis (18).

The relationship, if any, between blood metalloproteinases and chemokines and $\mathrm{O}_{2}$ administration has not been previously evaluated in neonates. The hypothesis of the current exploratory investigation was that $\mathrm{O}_{2}$ exposure immediately after birth is associated with altered blood spot MMP 9 and $\beta$ chemokine levels. Our broad intent was to determine whether MMP 9 or any of the $\beta$ chemokines, which seem to be induced by oxygen free radicals in experimental data, were markers of oxidative exposure in extremely preterm infants. For this purpose, we evaluated blood levels on $\mathrm{d} 1$ (within $4 \mathrm{~h}$ of birth) and 3; the initial sample served as a baseline, and the second sample was taken at a time point when many potential confounders were avoided, and yet, infants in the "prolonged early $\mathrm{O}_{2}$ group" had already suffered sustained $\mathrm{O}_{2}$ exposure. Our specific aims were a) to compare blood spot MMP 9 and $\beta$ chemokines (MCP 1, MIP $1 \alpha$ and $\beta$, and RANTES) on $\mathrm{d} 1$ and 3 among extremely preterm infants who required $\mathrm{O}_{2}$ at $6 \mathrm{~h}$ of life continuing through age $24 \mathrm{~h}$ and those with brief $(<6$ h) or no exposure; b) to examine the changes in circulating levels of MMP 9 and $\beta$ chemokines from $d 1$ to 3 in the two subgroups of infants with differential duration of oxygen exposure; c) to correlate blood MMP 9 and $\beta$ chemokines on d 1 and 3 of life with the highest fraction of inspired oxygen $\left(\mathrm{FiO}_{2}\right)$ administered at the corresponding time points; and $\left.\mathrm{d}\right)$ to evaluate whether $\mathrm{O}_{2}$ exposure was an independent determinant of blood MMP 9 and $\beta$ chemokine concentrations, after adjusting for other variables.

\section{PATIENTS AND METHODS}

Study population. The results of this study are derived from the secondary analyses of data collected from preterm infants who participated in the "Inflammatory Cytokines and Neurodevelopmental Outcomes in Extremely Low Birth Weight Infants" study of the NICHD multicenter Neonatal Research Network (Carlo WA et al., Inflammatory Cytokines and neurodevelopmental outcomes in extremely low birth weight infants, 2007 PAS Annual Meeting, May 5-8, 2007, Toronto, Canada, Abstract 615350.5.21). The study was approved by the institutional review boards of all participating centers (Supplemental material, http://links.lww.com/PDR/A53), and informed parental consent was obtained. The study population comprised preterm infants with birth weights between 401 and $1000 \mathrm{~g}$ of both genders and all racial or ethnic groups.

Study interventions. Neonatal data, including details of delivery room (DR) resuscitation, gestation, race, gender, 5-min Apgar score, number of doses of surfactant administered, use of high frequency ventilation, and maternal data including antenatal steroids, were prospectively collected. Data on "early onset sepsis," defined as bacteremia within $72 \mathrm{~h}$ of birth and use of "antibiotics for 5 or more days" initiated within the first $72 \mathrm{~h}$ were also obtained. The data collection form recorded prolonged early $\mathrm{O}_{2}$ exposure as a requirement for "supplemental oxygen $\left(\mathrm{FiO}_{2}>0.21\right)$ continuously from $6 \mathrm{~h}$ of life to $24 \mathrm{~h}$ of age." The highest administered $\mathrm{FiO}_{2}$ on $\mathrm{d} 1$ and 3 of life were also recorded.

Blood samples (whole blood spots, dried on filter paper) were obtained on $\mathrm{d} 1$ (within $4 \mathrm{~h}$ of birth) and on d $3 \pm 1$ of life. Blood samples were obtained from indwelling arterial or venous lines or from heel sticks if an indwelling line was not available. For each sample, blood was used to fill each of two circles on filter paper. The samples were allowed to dry at room temperature and then stored in a freezer.

Assay for MMP 9 enzyme and $\beta$ chemokines was performed with a multiplex assay using luminex (xMAP) (Luminex Corp, Austin, TX) technology (21). This technology is known to have a sensitivity comparable with traditional ELISA-based systems but with advantages of an extended dynamic range. It combines the principle of a sandwich immunoassay with fluorescent bead-based technology.

Data analysis. We used nonparametric methods of statistical analysis wherever possible, acknowledging the skewed nature of the $\beta$ chemokine and MMP 9 measurements. Descriptive statistics included medians and 25th and 75th quartile ranges of $\beta$ chemokines and MMP 9 at the time points when blood samples were obtained. Wilcoxon test was used to compare the two groups at each time point. Postnatal changes from d 1 to 3 were compared in the two groups of infants, using median regression, after adjusting for covariates. Correlations between plasma concentrations on d 1 and 3 of life and the highest $\mathrm{FiO}_{2}$ at the corresponding time points were examined using Spearman rank correlation coefficients. Significant correlations were further examined, using median regression, after adjusting for covariates. Because of the skewed data, median regression analysis was also performed to determine whether $\mathrm{O}_{2}$ exposure was an independent determinant of MMP 9 and chemokine levels, after adjusting for covariates. Gestation, gender, 5-min Apgar score, antenatal steroids, early onset sepsis, and severity of respiratory illness were used as covariates. Severity of respiratory illness was defined as surfactant doses $>2$ or the need for high frequency ventilation. In view of multiple comparisons, a $p$ value of $<0.01$ was taken as statistical significance. Data were analyzed using SAS version 9.1.3 (SAS Institute, Cary, NC).

\section{RESULTS}

Clinical data. A total of 1067 extremely preterm infants participated in the "Inflammatory Cytokines and Neurodevelopmental Outcomes in Extremely Low Birth Weight Infants" study of the NICHD multicenter Neonatal Research Network (Carlo WA et al., Inflammatory Cytokines and neurodevelopmental outcomes in extremely low birth weight infants, 2007 PAS Annual Meeting, May 5-8, 2007, Toronto, Canada, Abstract 615350.5.). Of these, 8 infants had missing data; 729 infants received $\mathrm{O}_{2}$ at $6 \mathrm{~h}$ of life continuing through $24 \mathrm{~h}$ of age (defined as prolonged early oxygen exposure), and 330 received oxygen for less than $6 \mathrm{~h}$ (Fig. 1). Infants with a sample at either time point were included; 158 infants in the brief $\mathrm{O}_{2}$ group and 335 in the early prolonged $\mathrm{O}_{2}$ group had both samples. Table 1 compares the demographic characteristics of the two groups. The group with more prolonged early oxygen administration was significantly more premature, had lower mean birth weight, was intubated in the DR more often, and had a higher incidence of respiratory distress syndrome (RDS) with a greater need for surfactant (all $p \leq 0.002$ ). A significantly greater proportion of these infants were treated

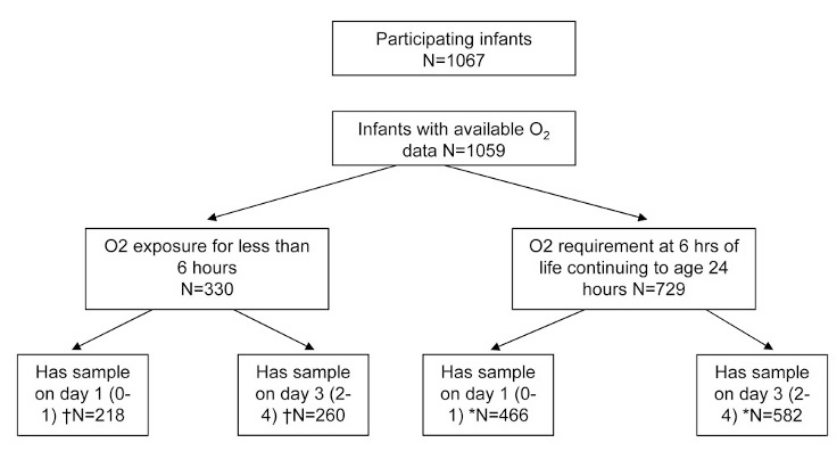

Figure 1. Flowchart of infants in the study and the duration of oxygen exposure. 
Table 1. Baseline characteristics of infants exposed to oxygen through the initial $24 \mathrm{~h}$ of age and those not exposed

\begin{tabular}{|c|c|c|c|}
\hline Variable & $\begin{array}{c}\mathrm{O}_{2} \text { requirement } \\
\text { continuously from } \\
6 \text { to } 24 \mathrm{~h}, N(\%) \text { or } \\
\text { mean }(\mathrm{SD})(N=729)\end{array}$ & $\begin{array}{c}\mathrm{O}_{2} \text { exposure } \\
<6 \mathrm{~h}, N(\%) \\
\text { or mean }(\mathrm{SD}) \\
(N=330)\end{array}$ & $\begin{array}{r}p \text { (Fisher's } \\
\text { exact test } \\
\text { or linear } \\
\text { regression) }\end{array}$ \\
\hline Birth weight (g) & 747 (141) & 793 (134) & $<0.001$ \\
\hline $\begin{array}{l}\text { Gestational age } \\
\text { (wk) }\end{array}$ & $26(1.8)$ & $27(2.1)$ & $<0.001$ \\
\hline SGA & $77(11 \%)$ & $73(22 \%)$ & $<0.0001$ \\
\hline Gender: male & $363(50 \%)$ & $151(46 \%)$ & 0.23 \\
\hline Race: black & $346(47 \%)$ & $158(48 \%)$ & 0.95 \\
\hline AN steroids & $540(74 \%)$ & $262(80 \%)$ & 0.05 \\
\hline $\begin{array}{l}\text { Maternal antibiotics } \\
\text { in the admission } \\
\text { resulting in the } \\
\text { delivery }\end{array}$ & $509(70 \%)$ & $218(67 \%)$ & 0.31 \\
\hline 5 min Apgar $<5$ & $105(15 \%)$ & $34(11 \%)$ & 0.08 \\
\hline DR $\mathrm{FiO}_{2}$ (oxygen) & $721(99 \%)$ & $323(98 \%)$ & 0.15 \\
\hline DR intubation & $570(78 \%)$ & $228(69 \%)$ & 0.002 \\
\hline RDS & $717(98 \%)$ & $276(84 \%)$ & $<0.001$ \\
\hline Any surfactant & $645(88 \%)$ & $217(66 \%)$ & $<0.001$ \\
\hline Surfactant doses & $2.0(1.0)$ & $1.5(0.8)$ & $<0.001$ \\
\hline $\begin{array}{l}\text { High frequency } \\
\text { ventilation in } \\
\text { the } 1 \text { st } 24 \mathrm{~h}\end{array}$ & $39(5 \%)$ & $9(3 \%)$ & 0.06 \\
\hline Early onset sepsis & $14(2 \%)$ & $2(1 \%)$ & 0.17 \\
\hline Antibiotics $\geq 5 \mathrm{~d}$ & $391(54 \%)$ & $135(41 \%)$ & 0.002 \\
\hline
\end{tabular}

SGA, small for gestation; DR, delivery room; RDS, respiratory distress syndrome.

with antibiotics for $5 \mathrm{~d}$ or longer $(p=0.0002)$. The proportion of infants who were small for gestation was significantly higher (22 versus 11\%) in the group with brief oxygen requirement for $<6 \mathrm{~h}$. "Maternal antibiotics in the admission resulting in the delivery," a surrogate for chorioamnionitis did not differ in the two groups.

MMP 9, $\beta$ chemokines, and the relation with early prolonged oxygen exposure. Median and interquartile ranges of MMP 9 and $\beta$ chemokine concentrations in the two groups of infants with brief and prolonged $\mathrm{O}_{2}$ exposure on $\mathrm{d} 1$ and 3 are shown in Table 2. There was a considerable variation in each chemokine in both groups and both time points. MCP 1 on d 3 was significantly higher $(p<0.01)$, whereas RANTES on $\mathrm{d}$ 3 was significantly lower among infants with predefined prolonged early oxygen exposure $(p<0.01)$. MMP 9 and MIP $1 \alpha$ and $\beta$ were comparable in the two groups on both $\mathrm{d} 1$ and 3 .

Figure 2 reflects box and whisker plots of MMP 9 and the chemokines at the two sampling times in the two groups with differential $\mathrm{O}_{2}$ exposure. The fences in the plots show the most extreme observed values within $[\mathrm{Q} 3+(1.5 \times \mathrm{IQR})]$ for the upper fence or within $[\mathrm{Q} 1-(1.5 \times \mathrm{IQR})]$ for the lower fence. MMP 9 increased by about 35\% between d 1 and 3 of life, whereas all the $\beta$ chemokines showed a downward trend. All mediators showed similar postnatal changes in the two groups.

The relationship between $\mathrm{O}_{2}$ administration and MMP 9 and $\beta$ chemokine profiles was further examined using correlation analyses with the highest $\mathrm{FiO}_{2}$ at the corresponding periods. There were negative correlations betweem MMP 9 of d 1 and highest $\mathrm{FiO} 2$ at $24 \mathrm{~h}(\mathrm{r}=-0.12, p<0.002)$ and at $3 \mathrm{~d}(\mathrm{r}=-0.09, p<0.03)$, which remained significant on $\mathrm{d} 3$ $(p=0.001)$, after adjusting for covariates in a median regression model (Table 3). A statistically significant negative correlation was also observed between RANTES on d 3 and the highest $\mathrm{FiO}_{2}$ at $24 \mathrm{~h}$ and on $\mathrm{d} 3(r=-0.14$ and $-0.19, p<$ $0.0001)$. MCP 1 on $\mathrm{d} 3 \mathrm{had}$ a significant positive correlation with highest $\mathrm{FiO}_{2}$ at $24 \mathrm{~h}$ and on $\mathrm{d} 3(r=0.17$ and $r=0.25$, $p<0.0001$ ). Correlations between $3 \mathrm{~d}$ RANTES and MCP 1 with the highest $\mathrm{FiO}_{2}$ on $\mathrm{d} 3$ remained statistically significant ( $p=0.0004$ and $p<0.0001)$ on adjusted analyses.

Median regression was used to examine whether the relationship between $\mathrm{O}_{2}$ exposure and $\beta$ chemokine concentrations was independent, using gestation, gender, 5-min Apgar score, antenatal steroids, early onset sepsis, and severity of respiratory illness as covariates. Prolonged early $\mathrm{O}_{2}$ exposure was found to be independently associated with plasma MCP 1 on d $3(p=0.003)$ (Table 4). Gestational age was the other significant covariate for MCP 1.

\section{DISCUSSION}

Our results were derived from secondary analyses of data from a large cohort of extremely preterm infants who were enrolled in the NICHD Neonatal Research Network multicenter "Inflammatory Cytokines and Neurodevelopmental outcomes in extremely low birth weight infants" study. As was expected, the subgroup of infants who were administered $\mathrm{O}_{2}$ continually through $24 \mathrm{~h}$ of life were more immature, had significantly lower mean birth weight, and needed intubation, surfactant, and antibiotic therapy more often than the group with brief $(<6 \mathrm{~h})$ oxygen exposure. MMP 9 and $\beta$ chemokine (MIP $1 \alpha$ and $\beta$, MCP 1 and RANTES) concentrations in our population are higher than previously reported values for older children, using different techniques (22). Infants with prolonged early $\mathrm{O}_{2}$ exposure had elevated MCP 1 and lower RANTES on $\mathrm{d} 3$ than the group with brief $\mathrm{O}_{2}$ administration.

Table 2. Median (interquartile range) levels of inflammatory mediators at different time points in the groups with brief and prolonged early exposure to oxygen

\begin{tabular}{|c|c|c|c|c|}
\hline \multirow[b]{2}{*}{$\begin{array}{l}\text { Mediator median } \\
\text { (range) } \mathrm{ng} / \mathrm{mL}\end{array}$} & \multicolumn{2}{|c|}{ Day 1} & \multicolumn{2}{|c|}{ Day 3} \\
\hline & $\begin{array}{l}\text { Prolonged early } \mathrm{O}_{2} \text { exposure } \\
\qquad(N=466)\end{array}$ & $\begin{array}{l}\text { Brief } \mathrm{O}_{2} \text { exposure } \\
\qquad(N=218)\end{array}$ & $\begin{array}{l}\text { Prolonged early } \mathrm{O}_{2} \text { exposure } \\
\qquad(N=582)\end{array}$ & $\begin{array}{c}\text { Brief } \mathrm{O}_{2} \text { exposure } \\
\quad(N=260)\end{array}$ \\
\hline MMP 9 & $634(277-1482)$ & $683(304-1407)$ & $1048(481-2011)$ & $1024(576-2032)$ \\
\hline MCP 1 & $2.1(1.1-5.5)$ & $1.9(1.0-3.8)$ & $2.0 *(1.0-3.8)$ & $1.4 *(0.9-2.5)$ \\
\hline $\operatorname{MIP} 1 \alpha$ & $0.16(0.1-0.3)$ & $0.14(0.09-0.24)$ & $0.15(0.09-0.27)$ & $0.15(0.09-0.25)$ \\
\hline MIP $1 \beta$ & $0.99(0.70-1.44)$ & $0.92(0.66-1.28)$ & $0.86(0.62-1.17)$ & $0.89(0.65-1.24)$ \\
\hline RANTES & $74.1(50.3-116.1)$ & $83.7(44.9-128.3)$ & $69.9 *(39.9-112.6)$ & $80.4 *(49.7-137.9)$ \\
\hline
\end{tabular}

$* p<0.01$ (from Wilcoxon two-sample test, $\mathrm{t}$ approximation). 

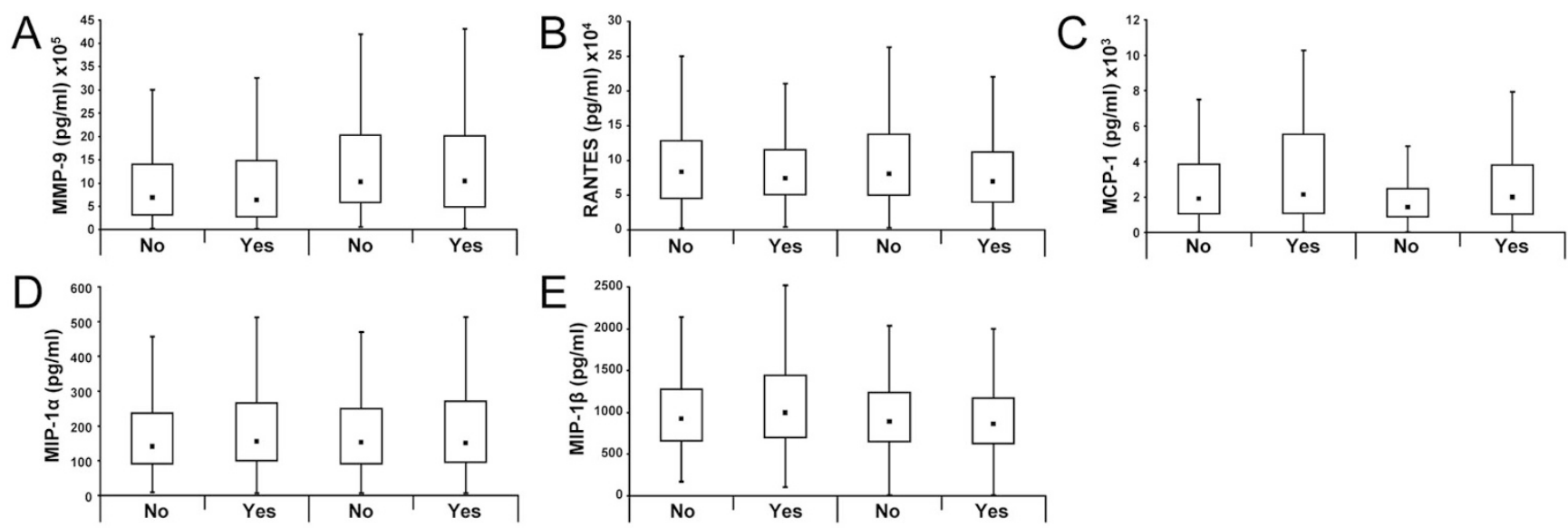

Figure 2. Box and whisker plots (with fences added as whiskers) of MMP 9 (A), RANTES (B), MCP 1 (C), MIP $1 \alpha$ (D), and MIP $1 \beta$ (E) on days 1 (within $4 \mathrm{~h}$ of birth) and 3 of age in the two groups with differential O2 exposure. These fences show the most extreme observed values within [Q3 $+(1.5 \times$ IQR $)]$ for the upper fence, or within [Q1 - $(1.5 \times \mathrm{IQR})]$ for the lower fence.

Table 3. Median regressions for correlation analyses, adjusting for covariates

\begin{tabular}{|c|c|c|c|}
\hline$p$ estimate $(95 \% \mathrm{CI})$ & Highest $\mathrm{FiO}_{2}$ at $24 \mathrm{~h}$ & Highest $\mathrm{FiO}_{2}$ at $3 \mathrm{~d}$ & Significant covariates \\
\hline MMP 9 day 1 & 0.02 & 0.001 & Gestation, RDS \\
\hline & $-412845(-613847,-243493)$ & $-538876(-770234,-313035)$ & \\
\hline MMP 9 day 3 & $\begin{array}{c}0.38 \\
-246474(-634229,448786)\end{array}$ & $\begin{array}{c}0.10 \\
-483043(-832948,93096)\end{array}$ & Gestation, antibiotics \\
\hline MCP 1 day 3 & $\begin{array}{c}0.57 \\
-9015(-38651,14986)\end{array}$ & $\begin{array}{c}0.0004 \\
-38086(-56778,-17988)\end{array}$ & Gestation, intubation \\
\hline RANTES day 3 & $\begin{array}{c}0.79 \\
84(-1598,1166)\end{array}$ & $\begin{array}{c}<0.0001 \\
2674(1608,3885)\end{array}$ & Gestation \\
\hline
\end{tabular}

\footnotetext{
* $p$ values from likelihood ratio tests.

$\dagger$ Covariates included: gestational age, delivery room intubation, RDS, and antibiotics $>5 \mathrm{~d}$.

RDS, respiratory distress syndrome; CI, confidence interval.
}

Table 4. Median regressions for oxygen exposure in the prediction of elevated levels of cytokines, adjusting for covariates

\begin{tabular}{llcc}
\hline & $p^{*}$ & Parameter estimate (95\% CI) $\dagger$ & Significant covariates $\neq$ \\
\hline MMP 9-1 d & 0.80 & $19512(-99921$ to 209885) & GA \\
MMP 9-3 d & 0.20 & $-117004(-325486$ to 12894) & GA, gender, RDS \\
MCP-1-3 d & 0.003 & $471(173-890)$ & GA \\
MIP-1 $\beta-1 \mathrm{~d}$ & 0.10 & $-35(-22$ to 217$)$ & EOS \\
MIP-1 $\beta-3 \mathrm{~d}$ & 0.47 & $-5836(-198$ to 56$)$ & Apgar5, EOS \\
RANTES-3 d & 0.18 & None & \\
\hline
\end{tabular}

\footnotetext{
$* p$ values from likelihood ratio tests.

$\dagger$ The parameter estimate can be interpreted as the adjusted median difference in plasma levels between the two comparison groups (for example, $3 \mathrm{~d}$ MCP level for the oxygen exposed group is on average $471 \mathrm{pg} / \mathrm{mL}$ higher than that for the nonexposed group, after adjusting for covariates).

\$ Covariates included: gestational age, gender, 5 min Apgar $<5$, any ANS (including infants who received ANS but did not have a complete course), severity of RDS (defined as more than two doses of surfactant or any HFV $v s \geq 2$ doses of surfactant and no HFV) and EOS.

GA, gestational age; RDS, respiratory distress syndrome; HFV, high-frequency ventilation; EOS, early onset sepsis; CI, confidence interval.
}

MCP 1 on d 3 showed a significant positive and MMP 9 on $\mathrm{d}$ 1 and RANTES on d 3 showed modest negative correlations with the highest administered $\mathrm{O}_{2}$. The striking finding of our study was that early prolonged $\mathrm{O}_{2}$ exposure was independently associated with higher plasma MCP 1 on d 3, even after adjusting for other clinical variables.

In our cohort, circulating MMP 9 was considerably higher than has been reported in healthy adults [mean (SEM) 315.3 (29.9) $\mathrm{ng} / \mathrm{mL}$ ] and older children (mean 400.4-553 ng/mL), although concentrations measured using different techniques (zymography, ELISA and luminex technology) cannot be directly compared (23). Median MMP 9 levels in fetal plasma, in the setting of preterm labor, and preterm rupture of mem- branes are also lower than in our cohort (mean 89.3 and 102.5 $\mathrm{ng} / \mathrm{mL}$ ) (24). Only one previous published study provided normative data on plasma activities of MMP 9, measured by zymography and found these to be highest in preterm infants 33- to 36-wk gestation and to decline by 50\% after $\mathrm{d} 1$ (25). Contrary to previous studies that show an elevation in bronchoalveolar lavage fluid or lung tissue MMP 9 in association with hyperoxia, we found only a modest negative correlation between MMP 9 on $\mathrm{d} 1$ and highest $\mathrm{FiO}_{2}$ at $3 \mathrm{~d}(13-15)$. There are some potential reasons for this. MMP 9 is a proenzyme that is activated in the tissues; therefore, blood spot MMP 9 may not accurately reflect tissue-specific concentrations or enzymatic activities. In addition, the biologic effect of the MMPs is 
determined by the balance between the enzymes and their tissue inhibitors, the levels of which we did not evaluate (26).

$\beta$ chemokine concentrations on $\mathrm{d} 1$ and 3 of life in our study are broadly concordant with the limited previous published data, although somewhat higher (26). Serum MCP 1, MIP $1 \alpha$, and RANTES levels very similar to our data were reported in a study comparing these mediators among perinatally asphyxiated and perinatally infected term and preterm neonates and healthy controls, although the assay methodology was traditional ELISA (27). Our results validate the observation of others that preterm infants mount a robust chemokine response in the first few days of life. By using a different assay methodology of recycling immunoaffinity chromatography, however, Dammann et al. (28) reported very low median levels of MIP $1 \alpha$ and RANTES among a small group of 15 extremely low gestation infants, still higher than in the term counterparts.

Both early prolonged $\mathrm{O}_{2}$ administration and the highest $\mathrm{FiO}_{2}$ were associated with significantly lower RANTES on d 3. A significantly lower plasma RANTES has been previously reported in perinatally infected neonates and necrotizing enterocolitis and is shown to accurately predict the development of disseminated intravascular coagulation in severely infected infants $(27,29,30)$. In adults, circulating RANTES levels inversely correlate with acute physiological assessment and chronic health evaluation scores $(r=-0.7)$ and adverse outcomes (median $5.6 \mathrm{ng} / \mathrm{mL}$ in nonsurvivors versus 16.4 in survivors, $p<0.05$ ) (31). In a study involving adult hemodialyzed patients, a significant negative correlation was observed between RANTES levels and copper-zinc superoxide dismutase levels, an established marker of oxidative stress (32). Because, in our data, the group of infants with prolonged oxygen exposure was smaller, more immature and generally "sicker" and $\mathrm{O}_{2}$ administration was not independently predictive of plasma RANTES, we speculate that a lower RANTES may simply be associated with severity of illness, with which oxygen exposure is inextricably linked.

MCP 1 on d 3 was significantly higher among infants with early prolonged $\mathrm{O}_{2}$ exposure, correlated significantly with the highest $\mathrm{FiO} 2$, and on median regression, $\mathrm{O}_{2}$ was an independent predictor of plasma MCP1. These observations are in accord with the limited previous data in neonates. Maximal tracheal aspirate MCP 1 concentrations have been shown to be significantly higher in infants who were $\mathrm{O}_{2}$ dependent at $28 \mathrm{~d}$ and 36 wk postconceptional age and to correlate with the development of BPD and adverse outcomes (33,34). Higher tracheal aspirate MCP 1 during the first week have been reported among infants with RDS and pulmonary hemorrhage $(34,35)$. MCP 1 has been implicated in the pathogenesis of acute and chronic lung injury in animal studies and is a pathophysiologic mediator of excitotoxic brain injury in neonatal rats $(34,36)$. It is believed to be the predominant mediator of monocyte-macrophage activation (34). The mechanism of MCP 1 increase remains unclear. Therefore, it is certainly plausible that $\mathrm{O}_{2}$ may be the trigger for an elevated MCP 1 and its associated morbidities.

Our study has some limitations. We used sustained early oxygen exposure from 6 to $24 \mathrm{~h}$ of age as a surrogate measure of greater oxygen exposure. Although we compared two groups of infants with distinct durations of $\mathrm{O}_{2}$ exposure, the actual $\mathrm{FiO}_{2}$ and the $\mathrm{Po}_{2}$ in the blood is not available and may have varied among infants. In addition, circulating chemokine and metalloproteinase concentrations may not reflect lung tissue concentrations or tissue-specific oxidative injury. We did not have data on traditional assays of oxidative injury such as oxidized glutathione or urinary isoprostanes or on chorioamnionitis. Chorioamnionitis has been demonstrated to induce pulmonary and systemic inflammatory response, with elevated MMP 9 and cytokines in the bronchoalveolar lavage fluid, lung tissue, and cord blood (37-39). In addition, it is associated with a higher risk of preterm birth and may modulate early oxygen requirements through its effect on RDS $(40,41)$. We recognize that because of the marked baseline differences between the two groups, some of the major results may be due to an unexplained variance in the groups. Nonetheless, the fairly consistent association between oxygen and higher MCP 1 revealed in our exploratory analyses are novel, potentially important data on which to base further studies.

In summary, oxygen administration was associated with higher plasma MCP 1. This intriguing finding suggests that further investigation is needed to improve our understanding of its role in oxidative injury and utility as a quantifiable marker of oxidative stress in preterm infants. We speculate that MCP 1 may even provide a broad mechanistic link between oxygen, inflammation, and the causally related morbidities.

Acknowledgments. We thank our medical and nursing colleagues, the infants, and their parents who agreed to take part in this study.

\section{REFERENCES}

1. Haynes RL, Baud O, Li J, Kinney HC, Volpe JJ, Folkerth DR 2005 Oxidative and nitrative injury in periventricular leukomalacia: a review. Brain Pathol 15:225-233

2. Saugstad OD 1997 Bronchopulmonary dysplasia and oxidative stress: are we closer to an understanding of the pathogenesis of BPD? Acta Paediatr 86:1277-1282

3. Tin W, Milligan DW, Pennefather P, Hey E 2001 Pulse oximetry, severe retinopathy, and outcome at one year in babies of less than 28 weeks gestation. Arch Dis Child Fetal Neonatal Ed 84:F106-F110

4. Bashiri A, Burstein E, Mazor M 2006 Cerebral palsy and fetal inflammatory response syndrome: a review. J Perinat Med 34:5-12

5. Speer CP 2003 Inflammation and bronchopulmonary dysplasia. Semin Neonatol 8:29-38

6. Speer CP 2006 Inflammation and bronchopulmonary dysplasia: a continuing story. Semin Fetal Neonatal Med 11:354-362

7. Saugstad OD 2005 Oxidative stress in the newborn-a 30-year perspective. Biol Neonate 88:228-236

8. Markus T, Hansson S, Amer-Wahlin I, Hellstrom-Westas L, Saugstad OD, Ley D 2007 Cerebral inflammatory response after fetal asphyxia and hyperoxic resuscitation in newborn sheep. Pediatr Res 62:71-77

9. Bhandari V, Elias JA 2006 Cytokines in tolerance to hyperoxia-induced injury in the developing and adult lung. Free Radic Biol Med 41:4-18

10. Legrand C, Gilles C, Zahm JM, Polette M, Buisson AC, Kaplan H, Birembaut P, Tournier JM 1999 Airway epithelial cell migration dynamics. MMP-9 role in cell-extracellular matrix remodeling. J Cell Biol 146:517-529

11. Spinale FG 2002 Matrix metalloproteinases: regulation and dysregulation in the failing heart. Circ Res 90:520-530

12. Okamoto T, Akaike T, Sawa T, Miyamoto Y, van der Vliet A, Maeda H 2001 Activation of matrix metalloproteinases by peroxynitrite-induced protein Sglutathiolation via disulfide S-oxide formation. J Biol Chem 276:29596-29602

13. Munkeby BH, Borke WB, Bjornland K, Sikkeland LI, Borge GI, Lomo J, Rivera S, Khrestchatisky M, Halvorsen B, Saugstad OD 2005 Resuscitation of hypoxic piglets with $100 \% \mathrm{O}_{2}$ increases pulmonary metalloproteinases and IL-8. Pediatr Res 58:542-548

14. Gushima Y, Ichikado K, Suga M, Okamoto T, Iyonaga K, Sato K, Miyakawa H, Ando M 2001 Expression of matrix metalloproteinases in pigs with hyperoxiainduced acute lung injury. Eur Respir J 18:827-837 
15. Schock BC, Sweet DG, Ennis M, Warner JA, Young IS, Halliday HL 2001 Oxidative stress and increased type-IV collagenase levels in bronchoalveolar lavage fluid from newborn babies. Pediatr Res 50:29-33

16. D'Angio CT, LoMonaco MB, Chaudhry SA, Paxhia A, Ryan RM 1999 Discordant pulmonary proinflammatory cytokine expression during acute hyperoxia in the newborn rabbit. Exp Lung Res 25:443-465

17. D'Angio CT, Sinkin RA, LoMonaco MB, Finkelstein JN 1995 Interleukin-8 and monocyte chemoattractant protein-1 mRNAs in oxygen-injured rabbit lung. Am J Physiol 268:L826-L831

18. Pawlak K, Pawlak D, Mysliwiec M 2005 Circulating beta-chemokines and matrix metalloproteinase-9/tissue inhibitor of metalloproteinase-1 system in hemodialyzed patients-role of oxidative stress. Cytokine 31:18-24

19. Deng H, Mason SN, Auten RL Jr 2000 Lung inflammation in hyperoxia can be prevented by antichemokine treatment in newborn rats. Am J Respir Crit Care Med $162: 2316-2323$

20. Vozzelli MA, Mason SN, Whorton MH, Auten RL Jr 2004 Antimacrophage chemokine treatment prevents neutrophil and macrophage influx in hyperoxiaexposed newborn rat lung. Am J Physiol Lung Cell Mol Physiol 286:L488-L493

21. Skogstrand K, Thorsen P, Norgaard-Pedersen P, Schendel DE, Sorensen LC, Hougaard DM 2005 Simultaneous determination of 25 inflammatory markers and neurotrophins in neonatal dried blood spots by immunoassay xMAP technology. Clin Chem 51:1854-1866

22. Sullivan SE, Staba SL, Gersting JA, Hutson AD, Theriaque D, Christensen RD, Calhoun DA 2002 Circulating concentrations of chemokines in cord blood, neonates, and adults. Pediatr Res 51:653-657

23. Glowinska-Olszewska B, Urban M 2007 Elevated matrix metalloproteinase 9 and tissue inhibitor of metalloproteinase 1 in obese children and adolescents. Metabolism 56:799-805

24. Romero R, Chaiworapongsa T, Espinoza J, Gomez R, Yoon BH, Edwin S, Mazor M, Maymon E, Berry S 2002 Fetal plasma MMP-9 concentrations are elevated in preterm premature rupture of the membranes. Am J Obstet Gynecol 187:1125-1130

25. Schulz CG, Sawicki G, Lemke RP, Roeten BM, Schulz R, Cheung PY 2004 MMP-2 and MMP-9 and their tissue inhibitors in the plasma of preterm and term neonates. Pediatr Res 55:794-801

26. Cockle JV, Gopichandran N, Walker JJ, Levene MI, Orsi NM 2007 Matrix metalloproteinases and their tissue inhibitors in preterm perinatal complications. Reprod Sci 14:629-645

27. Fotopoulos S, Mouchtouri A, Xanthou G, Lipsou N, Petrakou E, Xanthou M 2005 Inflammatory chemokine expression in the peripheral blood of neonates with perinatal asphyxia and perinatal or nosocomial infections. Acta Paediatr 94:800-806

28. Dammann O, Phillips TM, Allred EN, O'Shea TM, Paneth N, Van Marter LJ, Bose C, Ehrenkranz RA, Bednarek FJ, Naples M, Leviton A; ELGAN Study Investigators
2001 Mediators of fetal inflammation in extremely low gestational age newborns Cytokine 13:234-239

29. Ng PC, Li K, Chui KM, Leung TF, Wong RP, Chu WC, Wong E, Fok TF 2007 IP-10 is an early diagnostic marker for identification of late-onset bacterial infection in preterm infants. Pediatr Res 61:93-98

30. Ng PC, Li K, Leung TF, Wong RP, Li G, Chui KM, Wong E, Cheng FW, Fok TF 2006 Early prediction of sepsis-induced disseminated intravascular coagulation with interleukin-10, interleukin-6, and RANTES in preterm infants. Clin Chem 52:11811189

31. Cavaillon JM, Adib-Conquy M, Fitting C, Adrie C, Payen D 2003 Cytokine cascade in sepsis. Scand J Infect Dis 35:535-544

32. Pawlak K, Pawlak D, Mysliwiec M 2004 Oxidative stress influences CC-chemokine levels in hemodialyzed patients. Nephron Physiol 96:p105-p112

33. Baier RJ, Loggins J, Kruger TE 2001 Monocyte chemoattractant protein 1 and interleukin 8 are increased in bronchopulmonary dysplasia: relation to isolation of Ureaplasma urealyticum. J Investig Med 49:362-369

34. Baier RJ, Majid A, Parupia H, Loggins J, Kruger TE 2004 CC chemokine concentrations increase in respiratory distress syndrome and correlate with development of bronchopulmonary dysplasia. Pediatr Pulmonol 37:137-148

35. Baier RJ, Loggins J, Kruger TE 2002 Increased interleukin 8 and monocyte chemoattractant protein 1 concentrations in mechanically ventilated preterm infants with pulmonary hemorrhage. Pediatr Pulmonol 34:131-137

36. Galasso JM, Liu Y, Szaflarski J, Warren JS, Silverstein FS 2000 Monocyte chemoattractant protein 1 is a mediator of acute excitotoxic injury in neonatal rat brain. Neuroscience 101:737-744

37. Paananen R, Husa AK, Vuolteenaho R, Herva R, Kaukola T, Hallman M 2009 Blood cytokines during the perinatal period in very preterm infants: relationship of inflammatory response and bronchopulmonary dysplasia. J Pediatr 154:39-43

38. Kramer BW 2008 Antenatal inflammation and lung injury: prenatal origin of neonatal disease. J Perinatol 28:S21-S27

39. Curley AE, Sweet DG, Thornton CM, O'Hara MD, Chesshyre E, Pizzotti J, Wilbourn MS, Halliday HL, Warner JA 2003 Chorioamnionitis and increased neonatal lung lavage fluid matrix metalloproteinase-9 levels: implications for antenatal origins of chronic lung disease. Am J Obstet Gynecol 188:871-875

40. Gupta M, Mestan KK, Martin CR, Pearson C, Ortiz K, Fu L, Stubblefield P, Cerda S, Kasznica JM, Wang X 2007 Impact of clinical and histologic correlates of maternal and fetal inflammatory response on gestational age in preterm births. J Matern Fetal Neonatal Med 20:39-46

41. Watterberg KL, Demers LM, Scott SM, Murphy S 1996 Chorioamnionitis and early lung inflammation in infants in whom bronchopulmonary dysplasia develops. Pediatrics 97:210-215 